\title{
Theory of Planned Behavior as a Theoretical Framework
}

\author{
Nguyen Thanh Dung \\ Foreign Trade University
}

Hanoi, 11 August 2020

Theory of planned behavior (TPB), which was developed by (Ajzen, 1991), provides a useful theoretical framework for researching human social behavior in various fields. TPB, an extension of the theory of reasoned action (TRA), proposes that attitude toward the behavior, subjective norms, and perceived behavioral control can predict intention, which, combined with perceived behavioral control, can predict behavior (Figure 1).

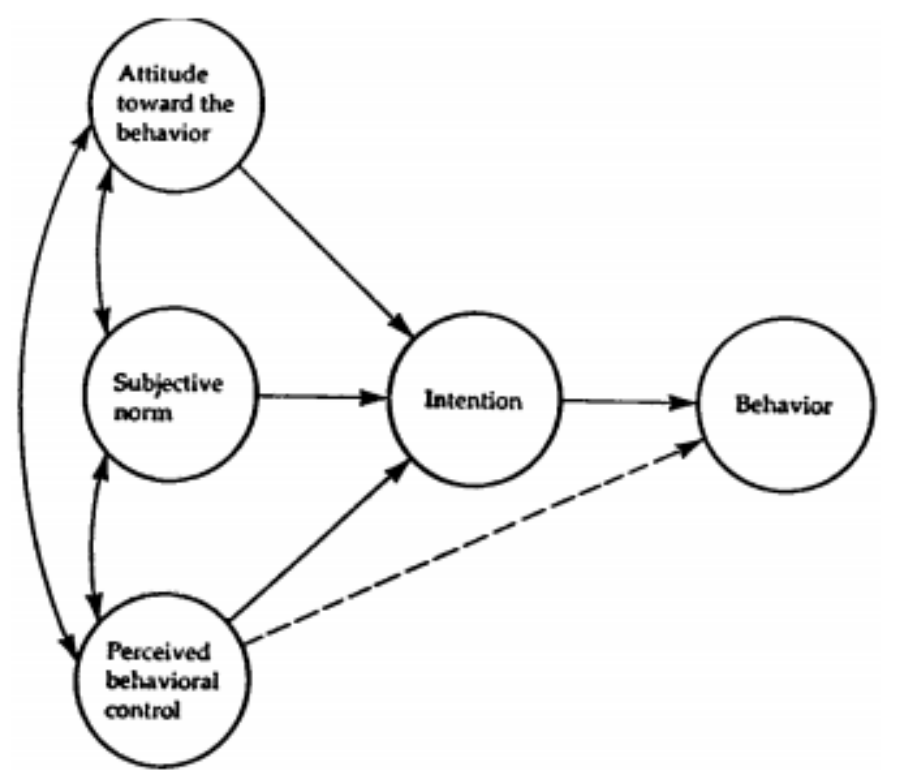

FIG. 1. Theory of planned behavior

Concepts employed in the model allow for the prediction of human intention and behavior in specific contexts. Attitude toward the behavior is defined as the extent to which the behavior is evaluated positively or negatively. Subjective norms refer to perceived social pressure on behavioral achievement. Perceived behavioral control reflects the ease or difficulty with which the behavior can take place. Generally, a more positive attitude, more favorable subjective norms, and higher perceived control are associated with stronger intention to perform the behavior.

In return, intention and perceived behavioral control can help predict the performance of the behavior. The stronger intention, i.e., stronger willingness to carry out the behavior, can lead to a higher probability of behavioral achievement. As in TRA, intention alone can predict behavior with high accuracy where people can behave at free will. Nevertheless, in most cases, faced with obstacles, people are more likely to conduct behavior when having a greater level of confidence (perceived behavioral control). 
By adding perceived behavioral control in the prediction of behavior, TPB represents an improvement over its predecessor, TRA (Han, Hsu, \& Sheu, 2010; Madden, Ellen, \& Ajzen, 1992; Marcoux \& Shope, 1997; Taylor \& Todd, 1995). This theory has been empirically proved in a wide range of fields such as healthcare, finance, marketing, commerce, transportation, leisure, sustainability, moral behavior ... (Ajzen \& Driver, 1992; Bamberg, Ajzen, \& Schmidt, 2003; Beck \& Ajzen, 1991; Cordano \& Frieze, 2000; Godin \& Kok, 1996; Han et al., 2010; Marcoux \& Shope, 1997; Pavlou \& Fygenson, 2006; Shih \& Fang, 2004; Taylor \& Todd, 1995; Yadav \& Pathak, 2016).

However, there are certain limitations to this theory. Firstly, the predictability of behavior depends on the measurement accuracy of the investigated variables. Secondly, variables like attitude, subjective norms, and perceived behavioral control were developed based on specific beliefs, yet this relationship remains uncertain and varies case by case. Even the same moral beliefs can differ across cultures (Vuong et al., 2020). Other concerns include the correlation and sufficiency of independent variables (Shah Alam \& Mohamed Sayuti, 2011). These need to be acknowledged in the limitation section of research papers for further development of the theory (Vuong, 2020).

\section{References}

Ajzen, I. (1991). The theory of planned behavior. Organizational Behavior and Human Decision Processes, 50(2), 179-211.

Ajzen, I., \& Driver, B. L. (1992). Application of the Theory of Planned Behavior to Leisure Choice. Journal of Leisure Research, 24(3), 207-224.

Bamberg, S., Ajzen, I., \& Schmidt, P. (2003). Choice of Travel Mode in the Theory of Planned Behavior: The Roles of Past Behavior, Habit, and Reasoned Action. Basic and Applied Social Psychology, 25(3), 175-187.

Beck, L., \& Ajzen, I. (1991). Predicting dishonest actions using the theory of planned behavior. Journal of Research in Personality, 25(3), 285-301.

Cordano, M., \& Frieze, I. H. (2000). Pollution Reduction Preferences of U.S. Environmental Managers: Applying Ajzen'S Theory of Planned Behavior. Academy of Management Journal, 43(4), 627-641. doi:10.5465/1556358

Godin, G., \& Kok, G. (1996). The Theory of Planned Behavior: A Review of its Applications to Health-Related Behaviors. American Journal of Health Promotion, 11(2), 87-98.

Han, H., Hsu, L.-T., \& Sheu, C. (2010). Application of the Theory of Planned Behavior to green hotel choice: Testing the effect of environmental friendly activities. Tourism Management, 31(3), 325-334.

Madden, T. J., Ellen, P. S., \& Ajzen, I. (1992). A Comparison of the Theory of Planned Behavior and the Theory of Reasoned Action. Personality and Social Psychology Bulletin, 18(1), 3-9. doi:10.1177/0146167292181001

Marcoux, B. C., \& Shope, J. T. (1997). Application of the Theory of Planned Behavior to adolescent use and misuse of alcohol. Health Education Research, 12(3), 323-331.

Pavlou, P. A., \& Fygenson, M. (2006). Understanding and Predicting Electronic Commerce Adoption: An Extension of the Theory of Planned Behavior. MIS Quarterly, 30(1), 115-143.

Shah Alam, S., \& Mohamed Sayuti, N. (2011). Applying the Theory of Planned Behavior (TPB) in halal food purchasing. International Journal of Commerce and Management, 21(1), 8-20. 
Shih, Y. Y., \& Fang, K. (2004). The use of a decomposed theory of planned behavior to study Internet banking in Taiwan. Internet Research, 14(3), 213-223.

Taylor, S., \& Todd, P. (1995). Decomposition and crossover effects in the theory of planned behavior: A study of consumer adoption intentions. International Journal of Research in Marketing, 12(2), 137-155.

Vuong, Q.-H. (2020). Reform retractions to make them more transparent. Nature, 582(7811), 149.

Vuong, Q.-H., Ho, M.-T., Nguyen, H.-K. T., Vuong, T.-T., Tran, T., Hoang, K.-L., . . La, V.-P. (2020). On how religions could accidentally incite lies and violence: folktales as a cultural transmitter. Palgrave Communications, 6(1), 82.

Yadav, R., \& Pathak, G. S. (2016). Young consumers' intention towards buying green products in a developing nation: Extending the theory of planned behavior. Journal of Cleaner Production, 135, 732-739. 